Article

\title{
Study on Lavender Essential Oil Chemical Compositions by GC-MS and Improved pGC
}

\author{
Guangyao Dong 1,2 Xiaohui Bai ${ }^{1,2}$, Aoken Aimila ${ }^{1,2}$, Haji Akber Aisa ${ }^{1,3}$ and \\ Maitinuer Maiwulanjiang $1,3, * \mathbb{C}$
}

1 The Key Laboratory of Plant Resources and Chemistry of Arid Zone, Xinjiang Technical Institute of Physics and Chemistry, Chinese Academy of Sciences, Urumqi 830011, China; donggh17@ms.xjb.ac.cn (G.D.); baixiaohui18@mails.ucas.ac.cn (X.B.); aimila16@ms.xjb.ac.cn (A.A.); haji@ms.xjb.ac.cn (H.A.A.)

2 School of Chemical Science, University of the Chinese Academy of Sciences, Beijing 100039, China

3 State Key Laboratory Basis of Xinjiang Indigenous Medicinal Plants Resource Utilization, Xinjiang Technical Institute of Physics and Chemistry, Chinese Academy of Sciences, Urumqi 830011, China

* Correspondence: mavlanjan@ms.xjb.ac.cn; Tel.: +86-0991-6631740; Fax: +86-0991-3838957

Academic Editor: Natalizia Miceli

Received: 3 June 2020; Accepted: 8 July 2020; Published: 10 July 2020

check for updates

\begin{abstract}
Lavender essential oil from the aerial parts of Lavandula angustifolia Mill. was analyzed by GC-MS equipped with three capillary columns of different polarities, which were HP-1, HP-5 ms and HP-INNOWax. A total of 40 compounds were identified by GC-MS, accounting for $92.03 \%$ of the total essential oil compositions. Nineteen monomers were separated by column chromatography and improved preparative gas chromatography (pGC), six of which could not be retrieved from the NIST 14 (National Institute of Standards and Technology, USA; 14th edition) library database. Fifteen compounds were identified for the first time in lavender essential oil. The improved pGC not only doubled the efficiency but also greatly reduced the cost.
\end{abstract}

Keywords: lavender; essential oil; improved preparative GC; NMR

\section{Introduction}

Lavender (Lavandula angustifolia Mill.) is a perennial herb and a member of the Lamiaceae (Labiatae) family that is native to the Mediterranean region and has been grown all over the world because of the huge market for essential oils. Lavender essential oil is widely used in fragrances and commodities including colognes, skin lotions, soaps, food flavorings, perfumes and aromatherapeutic medicines [1]. Lavender is also widely cultivated in China, and its main producing area is in Yili, Xinjiang. The Lavandula genus is divided into 37 varieties according to the shape of the leaves, corolla morphology, calyces and bract in "Lavender: The genus Lavandula" [2]. Only the essential oils of three lavender species (Lavandula angustifolia, Lavandula latifolia and Lavandula hybrid) play an important role in the perfume and cosmetics industry [3]. The essential oils of lavender are mainly produced from glands on the surface of the flowers and the leaves [2].

Although the chemical compositions of lavender essential oil were studied by GC-MS in different literatures $[4,5]$, there is no report on the separation and analysis of lavender essential oil by preparative gas chromatography (pGC), NMR and GC-MS equipped with three capillary columns of different polarities. This study could not only verify experimental results, but also the isolated monomer by pGC is of great help to the study of the activity of the single and composite component of lavender essential oil. The combination of these two methods can effectively solve the problem of identifying the accuracy of essential oil components by GC-MS without reference compounds. Therefore, the study has important analytical significance for identifying essential oil components. 
Many reports published have shown lavender essential oil to possess high cholinesterase inhibitory activities [6,7] and other biological activities beneficial to human health, such as being antibacterial, antifungal [8], sedative [9], anti-depressive, effective for burns and insect bites [10], anticancer [11], anti-spasmolytic, anti-inflammatory [12], antioxidant [13], acaricides etc. [14]. The main component of essential oils are terpenoids, which are low-molecular and lipophilic compounds that can easily cross the blood-brain barrier [15]. The compounds separated from lavender essential oil could lay the foundation for subsequent drug research.

\section{Results and Discussion}

\subsection{Chemical Composition of the Essential Oils}

The essential oil was extracted by hydrodistillation from the fresh plants of lavender aerial parts, and the mean values of the oil yields were $1.3 \%(v / w ; \mathrm{mL} / \mathrm{g})$ based on fresh weights. The essential oil GC-MS results of three different polarity capillary columns, which were HP-5 ms, HP-1 and HP-INNOWax capillary columns, are presented in Table 1 and Figures S1-S3 (Supplementary Materials). The relative content of the essential oil components was normalized by peak area and expressed as a percentage. The integration method is that $0.8 \%$ of the maximum peak area was selected as the minimum integral peak. According to the above integration method, 40 peaks could be identified by comparing their real retention indices relative to $n$-alkanes $\left(C_{7}-C_{30}\right)$ and mass spectra with the NIST 14 (National Institute of Standards and Technology, USA; 14th edition) Mass Spectral Library, which accounts for $92.03 \%$ of the total amount of essential oil compounds. The ninth peak can be determined as the mixed peak of the cis and trans isomer of the linalool oxide according to the GC-MS results of the HP-1 and HP-INNOWax capillary columns.

Forty compounds were identified in the essential oil by GC-MS, representing $92.03 \%$ of the total volatiles (Table 1). The identified monomers belong to different chemical classes and are present in different proportions. The essential oil contains essentially oxygenated monoterpenes (31.53\%) and esters $(43.23 \%)$, significant fraction monoterpene hydrocarbons $(8.03 \%)$, sesquiterpene hydrocarbons (3.61\%), oxygenated sesquiterpenes $(4.54 \%)$, and small quantities of other compounds (1.14\%). Linalool $(\mathbf{1 2}, 19.71 \%)$ - an oxygenated monoterpene-and linalyl acetate $(\mathbf{2 7}, \mathbf{2 6 . 6 1 \% )}$ and lavandulol acetate $(32,12.68 \%)$ - ester compounds-were the main components of the lavender essential oil.

The compounds that were separated by silica gel column chromatography and pGC were analyzed and identified by NMR (Figures S4-S21) (Supplementary Materials). Twelve compositions, which were compounds $9,10,12,13,17,18,21,27,32,38,39,40$ and 43 , were further identified by comparing the carbon spectrum data in the literature [16-28]. Compared with the method of determining compounds by GC-MS, six missing compositions, which were compounds 19, 29, 33, 41, 45 and 46, were identified by comparing the carbon spectrum data in the literature [29-34], and could not be retrieved from the NIST 14 database. By comparison with the literature [35], 15 compounds were newly identified. In this study, sulfur was isolated from essential oil for the first time, and was identified by GC-MS, whose mass spectrogram is shown in Figures S2 and S3 (Supplementary Materials). Therefore, it was proved that lavender essential oil contained a small amount of sulfur compounds. The sulfur compounds provide a new explanation for the insecticidal activity of lavender essential oil and provide a new research idea for later researchers. This finding may help to develop lavender essential oil into a new natural acaricides [36]. 
Table 1. Relative content and identified methods of the chemical compositions of lavender essential oil.

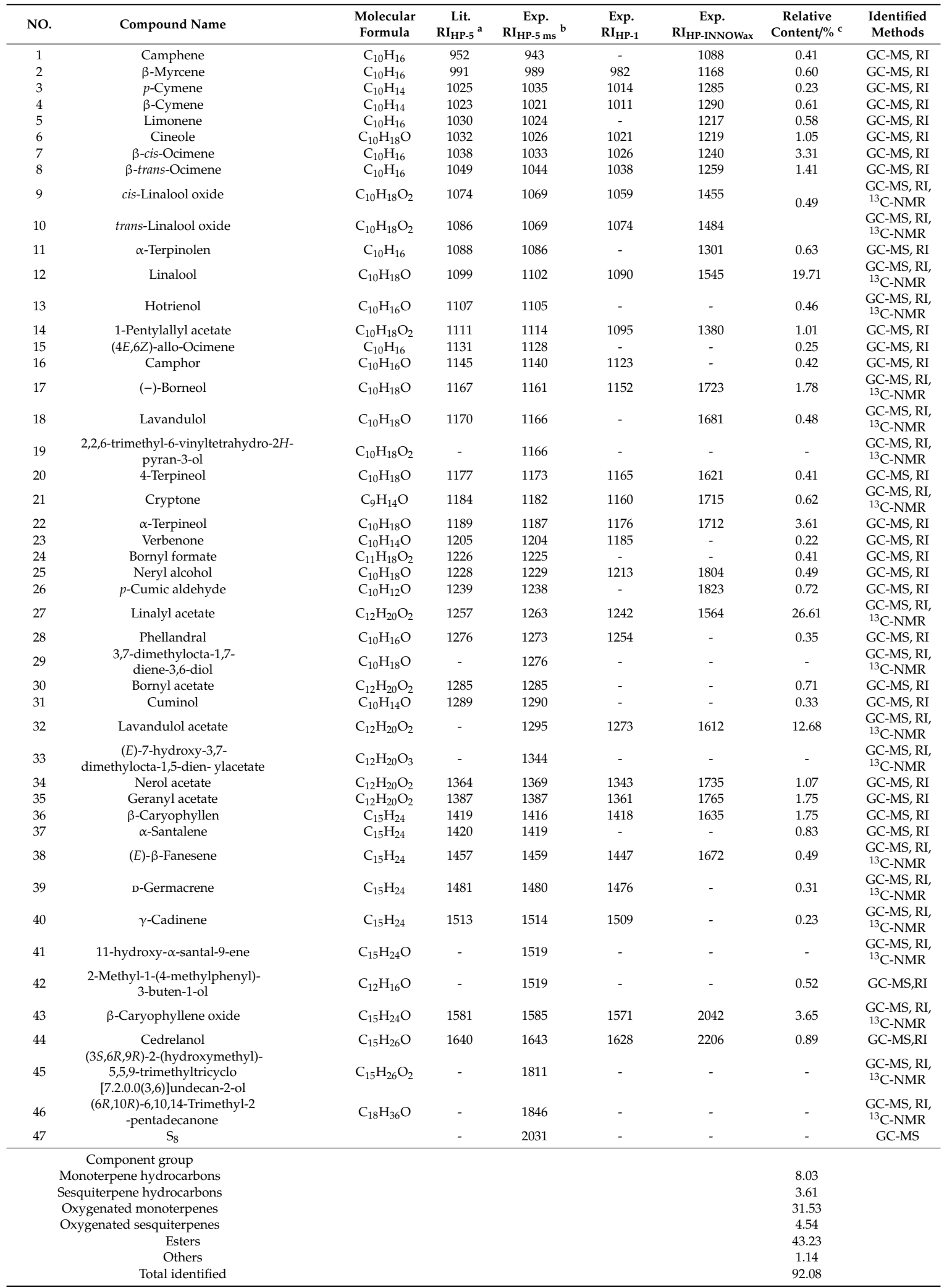

Bold type indicates major component. The blue type represents the newly identified compound. ${ }^{\text {a }}$ Literature retention indices (HP-5 column) according to NIST 14 (National Institute of Standards and Technology, USA; 14th edition) library database (https://webbook.nist.gov); ${ }^{\mathrm{b}}$ Experiment retention indices (HP-5 ms column); ${ }^{\mathrm{c}}$ Relative abundance calculated on HP-5 ms capillary column. 


\subsection{Improvements in the Fraction Collector of $p G C$}

In the early stages of the separation of lavender essential oils by pGC, we found that the cost and separation efficiency of this instrument were too low. To solve this problem, we converted the liquid nitrogen cooling system of the fraction collector to a cold trap cooling system. This improvement not only increased efficiency but also greatly reduced costs.

By improving the preparation fraction collector of pGC without affecting the normal operation of the pGC, it was found that the improved pGC had a similar collection amount in the same time and temperature compared with the unmodified equipment. The liquid nitrogen cooling system of the preparative fraction collector of pGC was transformed into a cold well cooling system. This improvement doubled the efficiency of preparative gas chromatography, and the cost of the cooling system was reduced from RMB 675/day to RMB 25/day.

\section{Materials and Methods}

\subsection{Plant Material and Reagents}

The aerial parts of Lavandula angustifolia Mill. were collected in June 2019 in Yili, Xinjiang, China. The plant material was dried in the shade. The plant sample was identified by Dr. Chunfang Lu and the voucher specimen was stored in the Xinjiang Technical Institute of Physics and Chemistry, Urumqi, Chinese Academy of Sciences (voucher species man No. WY02260). Anhydrous sodium sulfate was purchased from Tianjin Hongyan chemical reagent factory (Tianjin, China), $n$-hexane, ethyl acetate, and acetic acid were purchased from Tianjin Yongsheng Superfine Chemical Industry Co., Ltd. (Tianjin, China). n-Alkanes $\left(\mathrm{C}_{7}-\mathrm{C}_{30}\right)$ were purchased from Sigma-Aldrich (Shanghai, China).

\subsection{Extraction of the Essential Oil}

The lavender essential oil was obtained from aerial parts of the lavender that were cut into about $2 \mathrm{~cm}$ by hydrodistillation for $3 \mathrm{~h}$ using a self-assembling Clevenger-type apparatus, and the ratio of material to liquid was 1:10. The essential oil was collected, centrifuged, and taken from the upper layer. The lavender essential oil was extracted three times with $1200 \mathrm{~g}$ of material each time. The yields were $12.9852 \mathrm{~g}, 13.9137 \mathrm{~g}$ and $11.5129 \mathrm{~g}$, respectively. The upper layer (essential oil) was dried over $\mathrm{Na}_{2} \mathrm{SO}_{4}$ and stored at $-20^{\circ} \mathrm{C}$ until required for analysis and separation.

\subsection{Gas Chromatography Analysis}

The analysis of the essential oil was first performed on an Agilent GC-QTOF-MS system consisting of a 7890B gas chromatograph equipped with HP- $5 \mathrm{~ms}$ capillary column $(30 \mathrm{~m} \times 0.25 \mathrm{~mm}$ i.d., film thickness $0.25 \mu \mathrm{m}$ ) and 7693 autosampler, connected to a hybrid QTOF mass spectrometer (Agilent model 7200, Santa Clara, CA, USA), controlled by MassHunter Acquisition B.07.00 software (Santa Clara, CA, USA).

Helium was used as a carrier gas at a flow rate of $1 \mathrm{~mL} / \mathrm{min}$. The injector and detector temperatures were $250{ }^{\circ} \mathrm{C}$. The oven temperature was programmed from $70(10 \mathrm{~min})$ to $100{ }^{\circ} \mathrm{C}$ at a rate of $2{ }^{\circ} \mathrm{C} / \mathrm{min}$, then from 100 to $200^{\circ} \mathrm{C}$ at a rate of $5^{\circ} \mathrm{C} / \mathrm{min}$. The injection volumes were $0.4 \mu \mathrm{L}$. The split injection was conducted with a split ratio of 1:40. The mass spectra were recorded at $70 \mathrm{eV}(\mathrm{EI})$ and were scanned in the range $50-500 \mathrm{~m} / \mathrm{z}$.

The essential oil was analyzed on the Agilent GC-MS system consisting of a 7693 autosampler and 7890A gas chromatograph connected to a 5975C mass spectrometer (Santa Clara, CA, USA) (inert XL EI/CI MSD with Triple-Axis detector), controlled by 5975-7890GC-MS software (Santa Clara, CA, USA). The GC was equipped with HP-INNOWax ( $30 \mathrm{~m} \times 0.25 \mathrm{~mm}$ i.d., film thickness $0.25 \mu \mathrm{m})$ and HP-1 capillary columns $(30 \mathrm{~m} \times 0.25 \mathrm{~mm}$ i.d., film thickness $0.25 \mu \mathrm{m})$. Nitrogen was used as a carrier gas at a flow rate of $0.8 \mathrm{~mL} / \mathrm{min}$. The injector and detector temperatures were $250{ }^{\circ} \mathrm{C}$. The oven temperature was programmed from 60 to $180{ }^{\circ} \mathrm{C}$ at a rate of $8{ }^{\circ} \mathrm{C} / \mathrm{min}$, then from 180 to $240{ }^{\circ} \mathrm{C} \mathrm{(5} \mathrm{min)} \mathrm{at} \mathrm{a} \mathrm{rate} \mathrm{of}$ $10^{\circ} \mathrm{C} / \mathrm{min}$. The injection volumes were $0.8 \mu \mathrm{L}$. The split injection was conducted with a split ratio of 
1:40. The mass spectra were recorded at $70 \mathrm{eV}(\mathrm{EI})$ and were scanned in the range $30-500 \mathrm{~m} / \mathrm{z}$. The components were identified by comparing their real retention indices relative to the $n$-alkanes $\left(C_{7}-C_{30}\right)$ and the mass spectra with the NIST 14 Mass Spectral Library. The formula for calculating the retention index is as follows [36]:

$$
R I=100 Z+100\left(T_{x}-T_{z}\right) /\left(T_{z+1}-T_{z}\right)
$$

where $T_{X}$ is the component retention time; $Z$ is the carbon number of $n$-alkanes component; $T_{Z}$ is the the retention time of $n$-alkanes that carbon number is $Z$; and $T_{Z+1}$ is the the retention time of $n$-alkanes that carbon number is $\mathrm{Z}+1$.

\subsection{Isolation and Structure Elucidation}

The pGC was modified based on the Agilent 7890B gas chromatograph system (Agilent model 7200, Santa Clara, CA, USA). It was equipped with a HP-5 capillary column ( $30 \mathrm{~m} \times 0.53 \mathrm{~mm}$ i.d., film thickness $1.0 \mu \mathrm{m}$ ), a G4513A autosampler, a flame ionization detector (FID), a modular analytical system and a preparative fraction collector (Gerstel Company, Mülheim, Germany) equipped with a home-made cold trap cooling system.

In brief, $30.0 \mathrm{~g}$ of essential oil was firstly separated by silica gel column chromatography. The separation conditions were $380 \mathrm{~g}$, 200-300 mesh silica gel and $60 \times 600 \mathrm{~mm}$ column volume. The elution gradients were $n$-hexane:ethyl acetate $=100: 0,100: 1,100: 1.5,100: 3,100: 8,100: 15,100: 30,100: 50$, 0:100. According to the results of the thin layer, divided appropriately, the fractions were condensed to $4 \mathrm{~mL}$ and stored in brown vials at $-20^{\circ} \mathrm{C}$. Then, suitable fractions were selected to separate monomers by improved pGC. Seven fractions were selected to separate the compounds by pGC, which were successively named A-G. Compound 38 (3.0 mg), compound 39 (1.3 mg), and compound $40(0.8 \mathrm{mg})$ were prepared from A fractions by pGC. The injection volumes were $0.5 \mu \mathrm{L}$. The number of injections was 466 . The oven temperature of pGC was programmed from 70 to $160{ }^{\circ} \mathrm{C}$ at a rate of $50^{\circ} \mathrm{C} / \mathrm{min}$, then from 160 to $174{ }^{\circ} \mathrm{C}$ at a rate of $2{ }^{\circ} \mathrm{C} / \mathrm{min}$, and then from 174 to $280^{\circ} \mathrm{C}(0.5 \mathrm{~min})$ at a rate of $50{ }^{\circ} \mathrm{C} / \mathrm{min}$. Compounds $13(1.5 \mathrm{mg}), 18(1.9 \mathrm{mg}), 21(3.7 \mathrm{mg})$ and $41(0.7 \mathrm{mg})$ were prepared from $B$ fractions by pGC. The injection volumes were $0.5 \mu \mathrm{L}$. The number of injections was 411 . The oven temperature of pGC was programmed from 70 to $150{ }^{\circ} \mathrm{C}$ at a rate of $10^{\circ} \mathrm{C} / \mathrm{min}$, then from 150 to $250{ }^{\circ} \mathrm{C}(0.5 \mathrm{~min})$ at a rate of $50^{\circ} \mathrm{C} / \mathrm{min}$. Compounds $27(25.7 \mathrm{mg}), 32(15.3 \mathrm{mg}), 43(3.5 \mathrm{mg})$ and $46(1.4 \mathrm{mg})$ were prepared from $C$ fractions by pGC. The injection volumes were $1.0 \mu \mathrm{L}$. The number of injections was 524 . The oven temperature of pGC was programmed from 100 to $170{ }^{\circ} \mathrm{C}$ at a rate of $10^{\circ} \mathrm{C}$ per min, then from 170 to $250^{\circ} \mathrm{C}(1.5 \mathrm{~min})$ at a rate of $30^{\circ} \mathrm{C} / \mathrm{min}$. Compounds $18(3.8 \mathrm{mg}), 17(4.2 \mathrm{mg})$ and $41(0.3 \mathrm{mg})$ were prepared from $\mathrm{D}$ fractions by $\mathrm{pGC}$. The injection volumes were $1.0 \mu \mathrm{L}$. The number of injections was 435. The oven temperature of pGC was programmed from $150(5 \mathrm{~min})$ to $230^{\circ} \mathrm{C}$ at a rate of $20^{\circ} \mathrm{C} / \mathrm{min}$ $(1.5 \mathrm{~min})$. Compounds $10(5.2 \mathrm{mg})$ and $33(2.7 \mathrm{mg})$ were prepared from $\mathrm{E}$ fractions by pGC. The injection volumes were $1.0 \mu \mathrm{L}$. The number of injections was 376 . The oven temperature of pGC was programmed from 140 to $150{ }^{\circ} \mathrm{C}$ at a rate of $2{ }^{\circ} \mathrm{C} / \mathrm{min}$, then from 150 to $180^{\circ} \mathrm{C}$ at a rate of $10^{\circ} \mathrm{C} / \mathrm{min}$, then from 180 to $280^{\circ} \mathrm{C}(5 \mathrm{~min})$ at a rate of $100^{\circ} \mathrm{C} / \mathrm{min}$. Compound $29(27.5 \mathrm{mg})$ was prepared from $\mathrm{F}$ fractions by pGC. The injection volumes were $5.0 \mu \mathrm{L}$. The number of injections was 241 . The oven temperature of pGC was programmed from 100 to $240{ }^{\circ} \mathrm{C}(1.5 \mathrm{~min})$ at a rate of $20{ }^{\circ} \mathrm{C} / \mathrm{min}$. Compound $45(1.0 \mathrm{mg})$ was prepared from $\mathrm{G}$ fractions by pGC. The injection volumes were $4.0 \mu \mathrm{L}$. The number of injections was 431. The oven temperature of pGC was programmed from 100 to $200{ }^{\circ} \mathrm{C}$ at a rate of $25^{\circ} \mathrm{C} / \mathrm{min}$, then from 200 to $250^{\circ} \mathrm{C}(3 \mathrm{~min})$ at a rate of $20^{\circ} \mathrm{C} / \mathrm{min}$. The structure of the monomers was proved by ${ }^{13} \mathrm{C}-\mathrm{NMR}$.

\section{Conclusions}

In this study, the chemical composition of the lavender essential oil obtained from the aerial parts was studied by pGC and GC-MS equipped with three capillary columns of different polarity for the first time. Using GC-MS equipped with three capillary columns to analyze lavender 
essential oil made the composition accuracy of lavender essential oil more valuable for reference. Compared with the method of determining compounds by GC-MS, six missing compositions, which were 2,2,6-trimethyl-6-vinyltetrahydro-2 $\mathrm{H}$-pyran-3-ol, 3,7-dimethylocta-1,7-diene-3,6-diol, (E)-7-hydroxy-3,7-dimethylocta-1,5-dien-ylacetate, 11-hydroxy- $\alpha$-santal-9-ene, $(3 S, 6 R, 9 R)$-2-(hydroxymethyl)-5,5,9-trimethyltricyclo[7.2.0.0(3,6)]undecan-2-ol and $(6 R, 10 R)-6,10,14$-Trimethyl-2-pentadecanone, were identified. In comparison with the literature about lavender essential oil, 15 compounds were newly identified. The improved pGC not only doubled the efficiency but also greatly reduced the cost. This improved pGC also holds great promise.

Supplementary Materials: The supplementary data consist of the Figures S1-S21 and spectral data. Figure S1 showed GC-MS equipped with HP-5 ms, HP-1 and HP-INNOWax capillary columns TiC spectra for Lavender essential oil. Figures S2-S21 showed GC-EI-QTOF-MS Tic spectra, MS spectra and ${ }^{13} \mathrm{C}$ spectra for compounds $\mathbf{9}$, $10,12,13,17,18,19,21,27,29,32,33,38,39,40,41,43,45,46,47$.

Author Contributions: Conceptualization, H.A.A. and M.M.; Methodology, G.D.; investigation, G.D.; resources, A.A., X.B.; project administration, M.M.; supervision, M.M.; funding acquisition, H.A.A. and M.M.; writing—original draft, G.D.; writing—review \& editing, M.M. All authors have read and approved the manuscript.

Funding: This research was funded by the Recruitment Program of Global Experts awarded to Maiwulanjiang, and the Director Foundation of XTIPC, CAS (2016RC002).

Acknowledgments: This research was funded by the Recruitment Program of Global Experts awarded to Maiwulanjiang, and the Director Foundation of XTIPC, CAS (2016RC002).

Conflicts of Interest: The authors declare no conflict of interest.

\section{References}

1. Tabata, J.; Teshiba, M.; Shimizu, N.; Sugie, H. Mealybug mating disruption by a sex pheromone derived from lavender essential oil. J. Essent. Oil Res. 2015, 27, 232-237. [CrossRef]

2. Maria, L.-B. Lavender The Genus Lavandula; Taylor \& Francis: London, UK; New York, NY, USA, 2002; pp. 2-86.

3. Lubbe, A.; Verpoorte, R. Cultivation of medicinal and aromatic plants for specialty industrial materials. Ind. Crop. Prod. 2011, 34, 785-801. [CrossRef]

4. Imane, M.M.; Houda, F.; Amal, A.H.S.; Kaotar, N.; Mohammed, T.; Imane, R.; Farid, H. Phytochemical composition and antibacterial activity of moroccan Lavandula angustifolia mill. J. Essent. Oil. Bear. Plants 2017, 20, 1074-1082. [CrossRef]

5. Bialon, M.; Krzysko-Lupicka, T.; Nowakowska-Bogdan, E.; Wieczorek, P.P. Chemical composition of two different lavender essential oils and their effect on facial skin microbiota. Molecules 2019, 24, 3270. [CrossRef]

6. Ali-Shtayeh, M.S.; Abu-Zaitoun, S.Y.; Dudai, N.; Jamous, R.M. Downy lavender oil: A promising source of antimicrobial, antiobesity, and anti-alzheimer's disease agents. Evid.-Based Complementary Altern. 2020, 2020, 5679408. [CrossRef] [PubMed]

7. Al-Sarar, A.S.; Hussein, H.I.; Abobakr, Y.; Bayoumi, A.E.; Al-Otaibi, M.T. Fumigant toxicity and antiacetylcholinesterase activity of Saudi Mentha longifolia and Lavandula dentata species against Callosobruchus maculatus (F.)(Coleoptera: Bruchidae). Turk. Entomoloji Derg-Turk. 2014, 38, 11-18. [CrossRef]

8. Romeo, F.V.; De Luca, S.; Piscopo, A.; Poiana, M. Antimicrobial effect of some essential oils. J. Essent. Oil Res. 2008, 20, 373-379. [CrossRef]

9. Tomi, K.; Kitao, M.; Murakami, H.; Matsumura, Y.; Hayashi, T. Classification of lavender essential oils: Sedative effects of Lavandula oils. J. Essent. Oil Res. 2018, 30, 56-68. [CrossRef]

10. Cavanagh, H.M.A.; Wilkinson, J.M. Biological activities of Lavender essential oil. Phytother. Res. 2002, 16, 301-308. [CrossRef] [PubMed]

11. Sharifi-Rad, J.; Sureda, A.; Tenore, G.C.; Daglia, M.; Sharifi-Rad, M.; Valussi, M.; Tundis, R.; Sharifi-Rad, M.; Loizzo, M.R.; Ademiluyi, A.O. Biological activities of essential oils: From plant chemoecology to traditional healing systems. Molecules 2017, 22, 70. [CrossRef] [PubMed]

12. Carrasco, A.; Martinez-Gutierrez, R.; Tomas, V.; Tudela, J. Lavandula angustifolia and lavandula latifolia essential oils from spain: Aromatic profile and bioactivities. Planta Med. 2015, 82, 163-170. [CrossRef]

13. Woronuk, G.; Demissie, Z.; Rheault, M.; Mahmoud, S. Biosynthesis and therapeutic properties of lavandula essential oil constituents. Planta Med. 2011, 77, 7-15. [CrossRef] 
14. Adenubi, O.T.; Ahmed, A.S.; Fasina, F.O.; Mcgaw, L.J.; Eloff, J.N.; Naidoo, V. Pesticidal plants as a possible alternative to synthetic acaricides in tick control: A systematic review and meta-analysis. Ind. Crop. Prod. 2018, 123, 779-806. [CrossRef]

15. Wojtunik-Kulesza, K.A.; Targowska-Duda, K.; Klimek, K.; Ginalska, G.; Jozwiak, K.; Waksmundzka-Hajnos, M.; Ciesla, L. Volatile terpenoids as potential drug leads in Alzheimer's disease. Open Chem. 2017, 15, 332-343. [CrossRef]

16. Francisco, C.G.; Freire, R.; Hernández, R.; Salazar, J.A.; Suárez, E.; Cortés, M. Carbon-13 NMR study of (20,24)-epoxydammarane triterpenes. Magn. Reson. Chem. 1984, 22, 34-38. [CrossRef]

17. Shin, S.W.; Choi, S.H.; Lim, S. Combined Effects of the Essential Oil from Pelargonium graveolens with Antibiotics against Streptococcus pneumonia. Nat. Prod. Sci. 2007, 13, 342-346.

18. Schulz, S.; Steffensky, M.; Roisin, Y. Identification and synthesis of elymniafuran, a new monoterpene from the butterfly elymnias thryallis. Liebigs Ann. 1996, 6, 941-946. [CrossRef]

19. Choi, J.W.; Kim, K.H.; Lee, I.K.; Choi, S.U.; Lee, K.R. Phytochemical constituents of amomum xanthioides. Nat. Prod. Sci. 2009, 15, 44-49.

20. Miyazawa, M.; Nankai, H.; Kameoka, H. Enantioselective cyclization of (+/-)-lavandulol to (-)-(2S,4S)-1,5-epoxy-5-methyl-2-(1-methylethenyl)-4-hexanol by Glomerella cingulate. Nat. Prod. Lett. 1997, 9, 249-252. [CrossRef]

21. Queiroga, C.L.; Ferracini, V.L.; Marsaioli, A.J. Three new oxygenated cadinanes from baccharis species. Phytochemistry 1996, 42, 1097-1103. [CrossRef]

22. Guan, J.; Zhao, W.J.; Wei, J.J.; Gao, L. Studies on the chemical constituents of the extracts of lavender flowers from supercritical $\mathrm{CO}_{2}$ fluid. Lishizhen Med. Mater. Med. 2009, 20, 890-891. [CrossRef]

23. Bohlmann, F.; Zeisberg, R.; Klein, E. 13C-NMR-spektren von monoterpenen. Magn. Reson. Chem. 2005, 7, 426-432. [CrossRef]

24. Srivastava, P.L.; Daramwar, P.P.; Krithika, R.; Pandreka, A.; Shankar, S.S.; Thulasiram, H.V. Functional characterization of novel sesquiterpene synthases from indian sandalwood, santalum album. Sci. Rep. 2015, 5, 10095. [CrossRef] [PubMed]

25. Umlauf, D.; Zapp, J.; Becker, H.; Adam, K.P. Biosynthesis of the irregular monoterpene artemisia ketone, the sesquiterpene germacrene D and other isoprenoids in Tanacetum vulgare L. (Asteraceae). Phytochemistry 2004, 65, 2463-2470. [CrossRef] [PubMed]

26. Burkhardt, I.; Kreuzenbeck, N.; Beemelmanns, C.; Dickschat, J. Mechanistic characterization of three sesquiterpene synthases from the termiteassociated fungus Termitomyces. Org. Biomol. Chem. 2019, 17, 3348-3355. [CrossRef]

27. Ragasa, C.Y.; Ganzon, J.; Hofilena, J.; Tamboong, B.; Rideout, J.A. A new furanoid diterpene from Caesalpinia pulcherrima. Chem. Pharm. Bull. 2003, 51, 1208-1210. [CrossRef]

28. Weinert, B.; Wüst, M.; Mosandl, A.; Hanssum, H. Stereoisomeric flavour compounds. LXXVIII. Separation and structure elucidation of the pyranoid linalool oxide stereoisomers using common gas chromatographic phases, modified cyclodextrin phases and nuclear magnetic resonance spectroscopy. Phytochem. Anal. 1998, 9, 10-13. [CrossRef]

29. Strauss, C.R.; Wilson, B.; Rapp, A.; Guentert, M.; Williams, P.J. New monoterpene ethyl ethers in grape wines and brandies. J. Agric. Food Chem. 1985, 33, 706-708. [CrossRef]

30. Mookherjee, B.D.; Trenkle, R.W. Isolation, identification, and biogenesis of bifunctional compounds in lavandin oil. J. Agric. Food Chem. 1973, 21, 298-302. [CrossRef]

31. Ngo, K.S.; Brown, G.D. Santalane and isocampherenane sesquiterpenoids from illicium tsangii. Phytochemistry 1999, 50, 1213-1218. [CrossRef]

32. Singh, D.; Kumar Chaudhuri, P.; Darokar, M.P. New antiproliferative tricyclic sesquiterpenoid from the leaves of Ocimum sanctum. Helv. Chim. Acta 2014, 97, 708-711. [CrossRef]

33. Gao, Y.; Yang, W.Q.; Wang, F.; Liu, J.K.; Gao, J.M. Chemical component from allelopathic cultivar sunflower leaves. Acta Bot. Boreali-Occident. Sin. 2007, 27, 532-536. [CrossRef]

34. De Andrade, D.J.; Pattaro, F.C.; De Oliveira, C.A.L. Lime sulfur residue on acaricide efficiency in the control of Brevipalpus phoenicis. Cienc. Rural 2011, 41, 1695-1701. [CrossRef] 
35. Adaszynska-Skwirzynska, M.; Dzieciol, M. Comparison of chemical composition and antimicrobial activity of essential oils obtained from different cultivars and morphological parts of Lavandula angustifolia. J. Essent. Oil Bear. Plants 2018, 21, 1532-1541. [CrossRef]

36. Vandendool, H.; Kratz, P.D. A generalization of the retention index system including linear temperature programmed gas-liquid partition chromatography. J. Chromatogr. A 1963, 11, 463-471. [CrossRef]

Sample Availability: The data that support the findings of this study are available from the corresponding author upon reasonable request.

(C) 2020 by the authors. Licensee MDPI, Basel, Switzerland. This article is an open access article distributed under the terms and conditions of the Creative Commons Attribution (CC BY) license (http://creativecommons.org/licenses/by/4.0/). 